\title{
TESTING OF SPECIAL Ni-Mo STEEL AND ITS SUITABILITY FOR CUTTING TOOLS
}

\author{
Pavel Hanzl, Miroslav Zetek, Ivana Zetková \\ Department of Machining Technolog, University of West Bohemia in Pilsen, Univerzitní 22, 30614 Pilsen, \\ Czech Republic
}

\begin{abstract}
The aim of this article was to assess the suitability of newly applied Ni-Mo cutting steel for machinery of common steels. The biggest asset of Ni-Mo cutting steel is an easy heat treatment in comparison with other cutting tool materials. The Ni-Mo cutting steel heat treatment saves time and lowers demands on the thermal procedure. The Ni-Mo cutting steel was exposed to a cutting test and the result of these test was compared with the common tool steel DIN S 6-5-2 (W.Nr. 1.3343). Non-contact optical metrology system IFM G4 was used for determining the wear of cutting tools. The results proved an affinity of Ni-Mo steel to machined material. Therefore measures have been accepted to suppress this property.
\end{abstract}

Keyword: Special Ni-Mo steel; tool steel; effective machining; turning; tool life
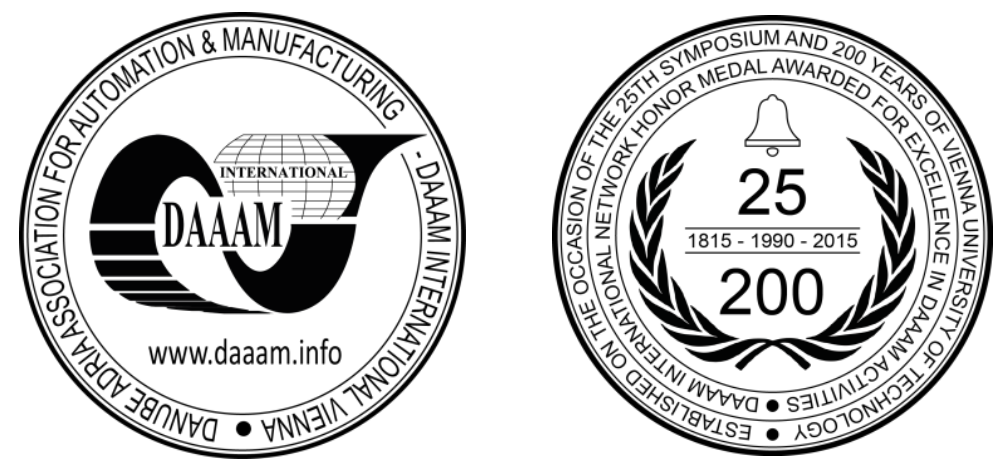

This Publication has to be referred as: Hanzl, P[avel]; Zetek, M[iroslav] \& Zetkova, I[vana] (2016). Testing of Special Ni-Mo Steel and its Suitability for Cutting Tools, Proceedings of the 26th DAAAM International Symposium, pp.0741-0747, B. Katalinic (Ed.), Published by DAAAM International, ISBN 978-3-902734-07-5, ISSN 1726-9679, Vienna, Austria

DOI:10.2507/26th.daaam.proceedings.103 


\section{Introduction}

Humanity has tried to ease the work of man since time immemorial. This led to the development of tools and with those also new materials. As a result of this effort, cutting tool steels and powder metallurgy were discovered during the last century. Their chemical composition and their manufacturing techniques have been gradually improved. Countless scientific articles were dedicated to the topic of extending tool life for specific applications. The following references shall be noted. Reference [1] concerns with tool life of ball nose end mill. Reference [2] is focused on tool wear during machining of nickel - based super alloys. However, the used cutting tool materials in these applications are very difficult to manufacture and further must be manufactured according to exact procedures such as the tempering processes $[4,7]$. This reality causes the production of cutting tools from these advanced materials to be expensive and difficult to implement. It was one of the main reasons why our department started a research and development in this field. The aim is to enforce a cheaper tool steel, which does not demand strict adherence for the heat treatment (HT) technology, but would provide a sufficient cutting performance. [8] A special Ni-Mo steel was chosen for our intended outcome, and was subjected to a cutting test. The selected method of machining was "turning" and the machined iron alloy was C 45 (DIN). The results were compared with the high speed cutting tool steel DIN S 6-5-2, for which the heat treatment was very difficult. Obtained tool wears were measured with non-contact optical metrology system IFM G4 and optical microscope Multicheck PC 500.

\section{Characteristics of the cutting tool}

\subsection{Basic mechanical properties}

Material used for cutting tool requires specific properties known from the theory of machinery. These properties are essential to prevent premature wear of the cutting tool. Among those, hardness at elevated temperatures, chemical stability, toughness, abrasion resistance and good thermal conductivity are included. These properties are common functional requirements for cutting tools. The basic mechanical properties of Ni-Mo steel were obtained from destructive testing and are listed in table 1.

\begin{tabular}{lllll}
\hline & E [GPa] & Rp0.2 [MPa] & Rm [MPa] & $\varepsilon[\%]$ \\
\hline Without HT & $165 \pm 4$ & $1228 \pm 86$ & $1303 \pm 98$ & $13 \pm 2$ \\
$\mathrm{HT}\left(5 \mathrm{~h}, 490^{\circ} \mathrm{C}\right)$ & $191 \pm 2$ & $2001 \pm 42$ & $2206 \pm 71$ & $1.7 \pm 1$ \\
\hline
\end{tabular}

Table 1. The basic mechanical properties

\subsection{Metallographic of material}

Ni-Mo steel can be cured by a simple heat treatment which leads to a new material structure: the martensitic structure. The simple heat treatment comprises heating, maintaining predefined temperature and a gradual cooling. The metallographic image is shown in Figure 1, which was taken with confocal microscope Olympus Lext OLS3000XL in light mode.

In martensitic matrix heat treatment causes an even distribution of intermetallic precipitates rich in fine nickel. These precipitates reinforce the martensitic matrix. The heat treatment of the turning tool was done by slow heating and maintaining a temperature of $490{ }^{\circ} \mathrm{C}$ in an inert atmosphere. The tool is kept for 5 hours in this temperature and then the process is followed by a slow cooling in a furnace.

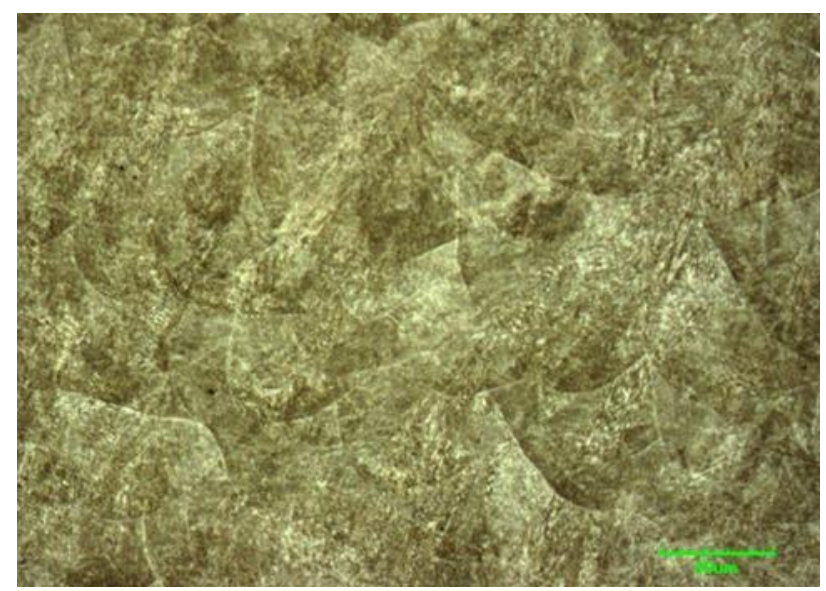

Fig. 1. The metallographic image after heat treatment 


\subsection{Hardness}

Table 2 shows material hardness before and after the heat treatment. The measurement was carried out on durometer Wolpert Wilson 432SVD. For comparison the high speed cutting tool steel DIN S 6-5-2 had hardness around 65 HRC.

\begin{tabular}{ll}
\hline & HV10 \\
\hline Before HT & $378-379(38,7$ HRC $)$ \\
After HT & $611-616(56,2$ HRC) \\
\hline
\end{tabular}

Table 2. Hardness of material before and after heat treatment

\subsection{Geometry of turning tools}

Because the experimental tests are performed on a lathe, the workpieces of tested materials are grinded into the shape of a turning tool. The geometry of the turning tool is dimensioned in a technical drawing, as shown in Appendix A. 1.

\section{Cutting Experiment}

Normalized and homogenized annealed steel material C 45 is machined for testing of the cutting performance. The cutting conditions are recorded in table 3.

The experiment is divided into three phases. During this testing, the values of wear were monitored, and agree with Fig. 2. Graphs show trends of wear in a relationship to the duration of the machining process.

\begin{tabular}{llll}
\hline Parameter & Value & Parameter & Value \\
\hline $\mathbf{K}_{\mathrm{r}}$ & $90^{\circ}$ & $\mathrm{n}$ & $63 \mathrm{ot} / \mathrm{min}$ \\
$\mathrm{a}_{\mathrm{p}}$ & $2 \mathrm{~mm}$ & $\emptyset \mathrm{d}$ & $85,0 \mathrm{~mm}$ \\
$\mathrm{f}$ & $0,125 \mathrm{~mm} / \mathrm{ot}$ & $\varnothing \mathrm{D}$ & $88,9 \mathrm{~mm}$ \\
\hline
\end{tabular}

Table 3. Cutting conditions

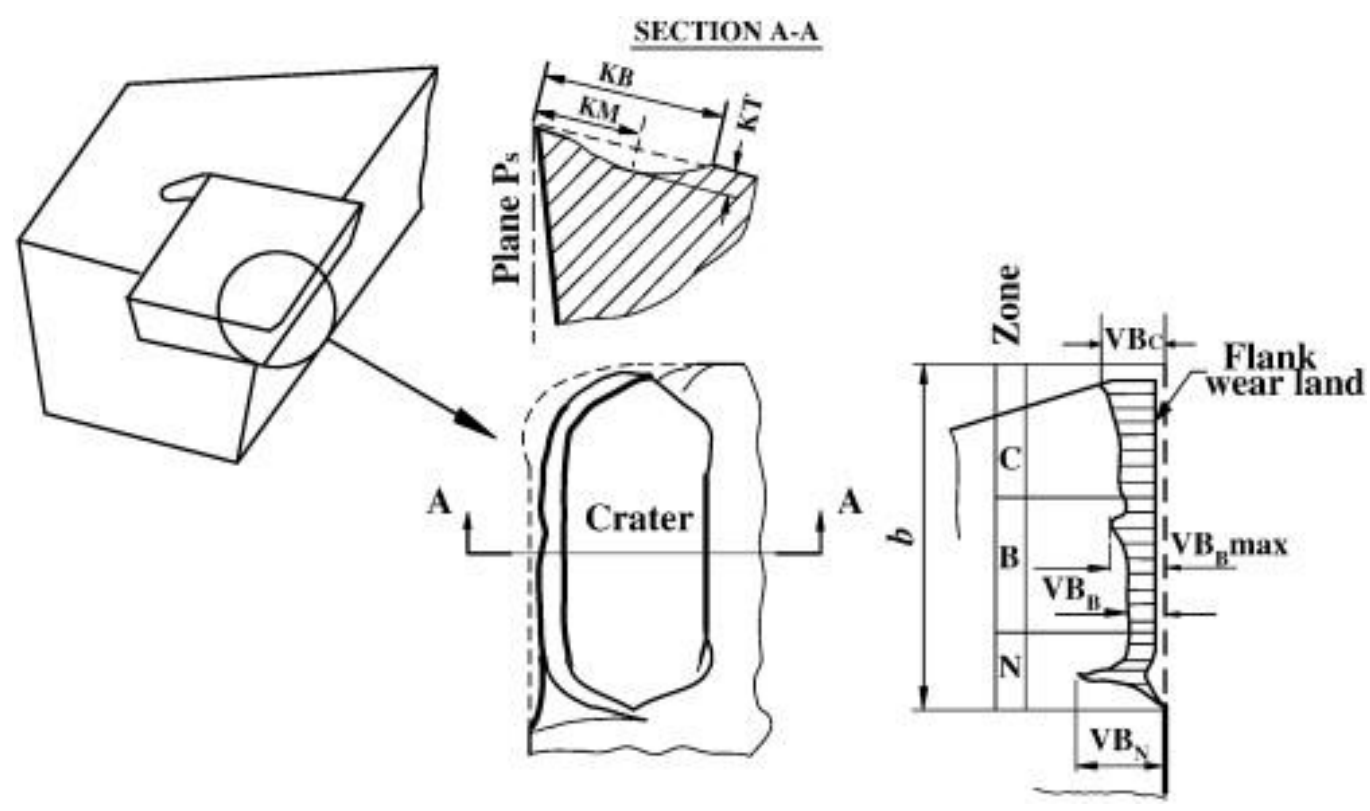

Fig. 2. Views of tool wear and their designations [5].

\subsection{First phase}

In the first phase the tested tool is performing a cutting process on a $58 \mathrm{~mm}$ long sample. The same conditions are used for the compared tool made out of high speed cutting steel. The images were taken by a microscope and are shown in Figure 3. On the left side of the figure we can observe considerable wear. On the right side of the figure is the compared tool. 


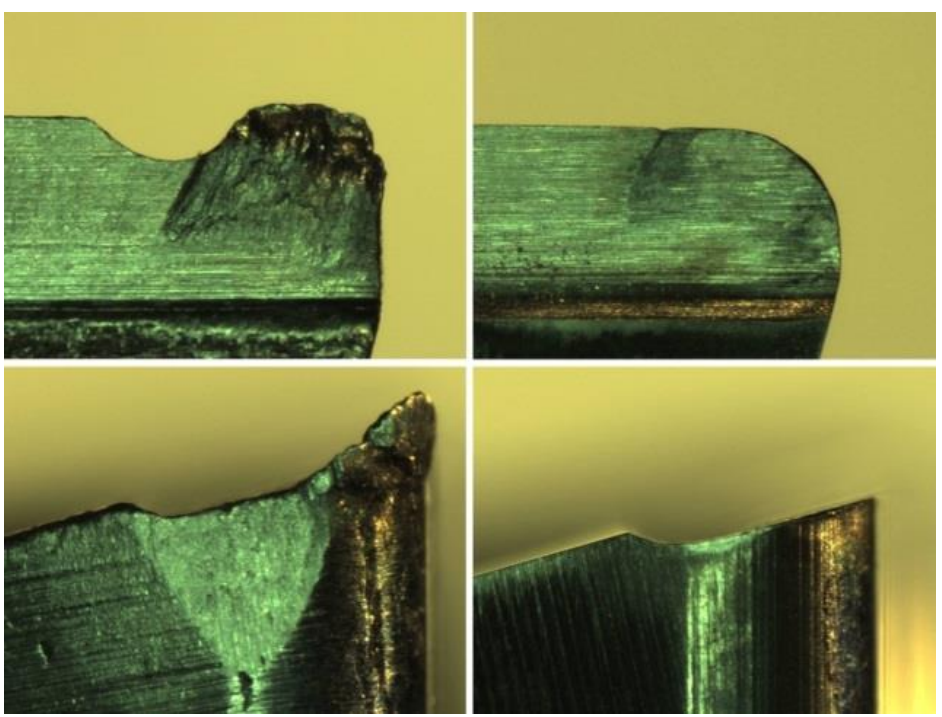

Fig. 3. Images of cutting tools after $58 \mathrm{~mm}$ cut; left images show the tested tool;right images show a cutting tool for comparison

From the figure 3 a build up edge (BUE) is apparent on the Ni-Mo cutting tool. Chemical affinity between the tested material and machined material is hereby inferred. This also explains the greater wear of rake face. The rake face wear arises from abrasive particles of the workpiece and from other diffusing processes. The tool wear of the cutting edge of the high speed cutting steel is $30 \mu \mathrm{m}$, and is uniform, which is generally considered to be ideal. The wear of the tested Ni-Mo steel is several times greater.

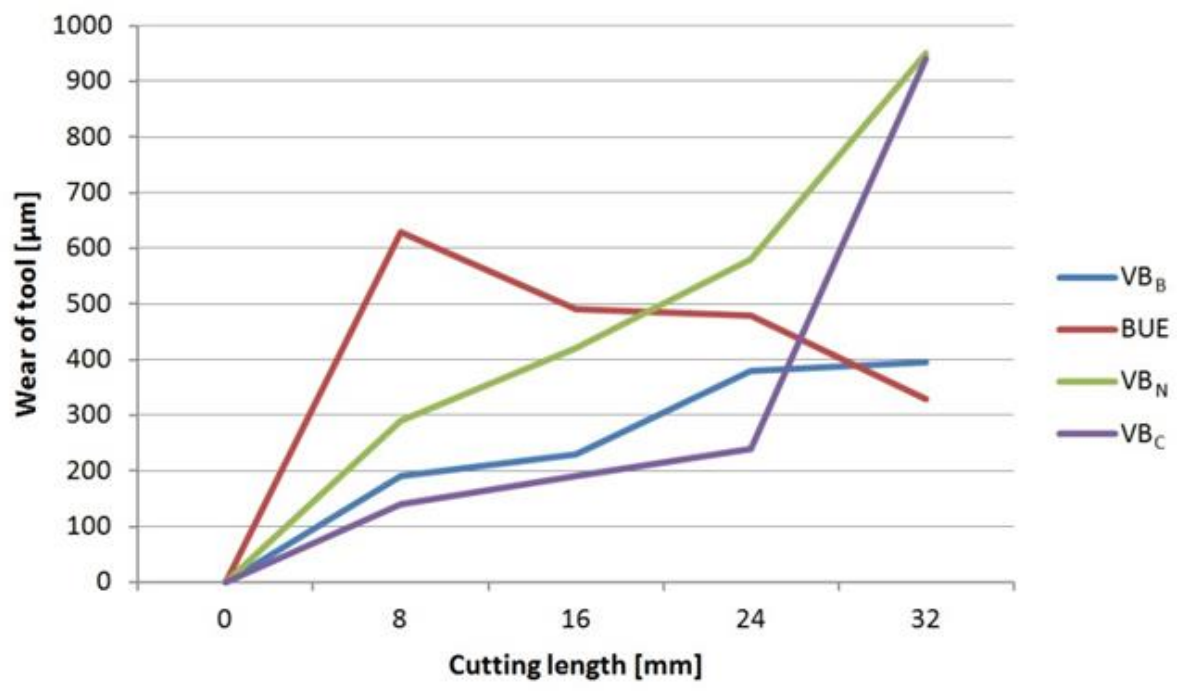

Fig. 4. The wear of cutting tool $\left(\mathrm{K} r=90^{\circ}\right)$

Tested tool is re-sharpened and undergoes the cutting process one more time for confirmation of previous results. This repetition confirms the obtained results. The curves of tool wear are shown in Figure 4.

The cause for the notch on the edge of the cutting tool was the improper removal of twisted chip. This chip rubs abrasively on the edge of the tool. During the effort to eliminate this notch, the angle of the main cutting edge was reduced from $90^{\circ}$ to $45^{\circ}$ and it defined the modification for phase 2 . The cutting conditions remained the same.

\subsection{Second phase}

The angle of the main edge is reduced from $90^{\circ}$ to $45^{\circ}$. Figure 5 shows the measurement outcome. The notch was significantly reduced. At the same time, the tool wear shows a steeper rise. The edge of the cutting tool contains a brittle fracture, which increases with the breakaway of BUE's. The wear of the turning tool is in general smaller than during phase one. The visual inspection of the workpiece surface shows better surface integrity than in the previous tests. 


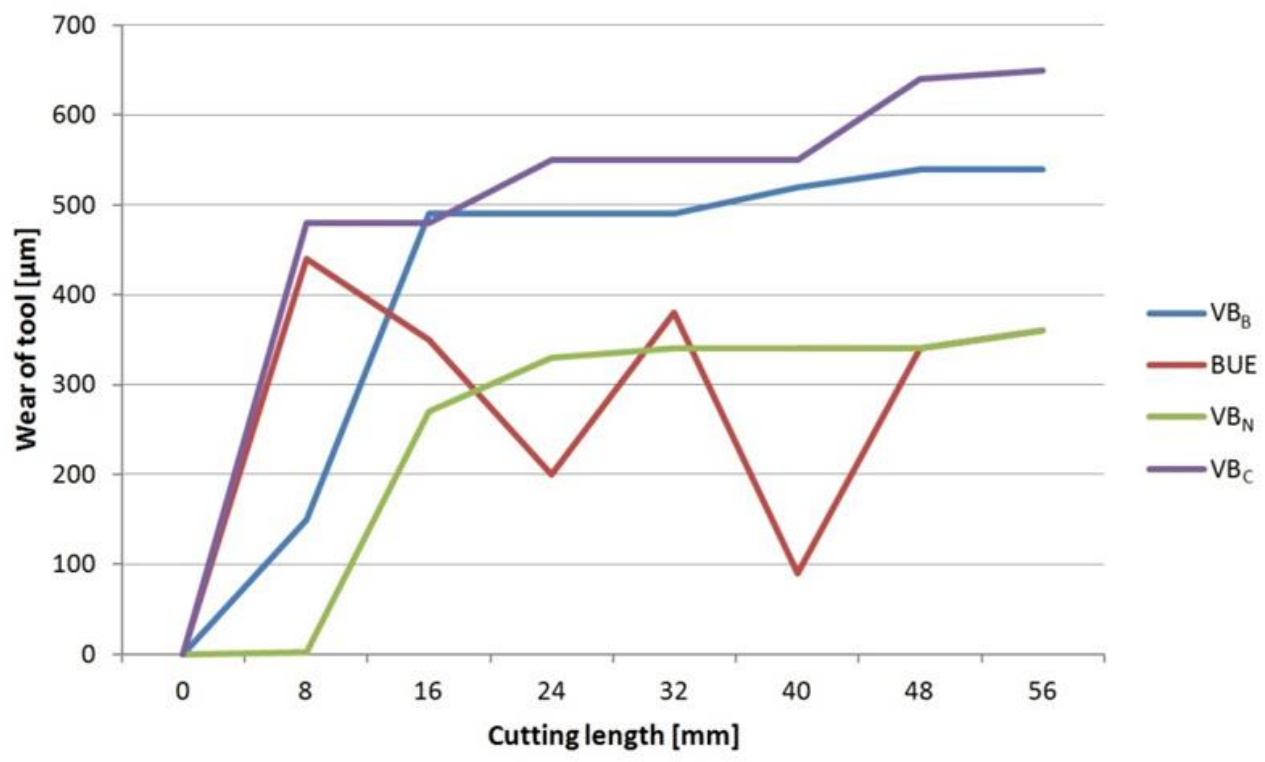

Fig. 5. The wear of cutting tool $\left(\mathrm{K} r=45^{\circ}\right)$

\subsection{Third phase}

The next step to improve the durability of the cutting edge of the tested tool is an effort to reduce the formation of BUE's. BUE can cause a brittle fracture on the cutting edge of the tool and changes its geometry.

Low temperatures and high pressure during manufacturing along with affinity tend to support the growth of BUE's. Increasing cutting speed in order to increase the temperature would be ill-fated because higher temperatures lower hardness of the cutting tool. Therefore the next step would be to reduce the affinity by applying a thin layer on the cutting tool so that the tool material would not be in direct contact with the workpiece material. This was done by applying a thin layer of Triple-Coating to the surface of the cutting tool. [3]

Triple-Coating is a trade mark of SHM company. As the name suggests, the coating consists of three layers

(Fig. 6). The first layer is in direct contact with the tool material and is made out of titan-nitrid (TiN). It forms a so called adhesive layer, which binds the next layers with the substrate. The second layer AlTiN is designed to provide toughness and firm support for the top layer. The top layer is made of CrAlSiN. This layer is very hard and resistant to penetration of foreign objects. [6]

This hard layer was applied to two samples of special Ni-Mo steel. The two samples differed in their heat treatment, i.e. hardening treatment was applied to one of them while the other was left untreated.

Adhesion of the thin coating layers to the material seems to be proper in both samples with or without thermal treatment.

Tests of microhardness, which penetrated the coating layers, showed nearly equal hardness in both samples. This indicates that the sample without heat treatment hardened during the application of the coating layer.

This finding can be interesting from an economic point of view. It could lead to a significant cost reduction of the heating treatment or even to a complete elimination of this cost.

The cutting tool is also coated with Triple-Coating layers and is tested under the same cutting conditions as in the phase 2. Obtained values of this test are shown in Figure 7.

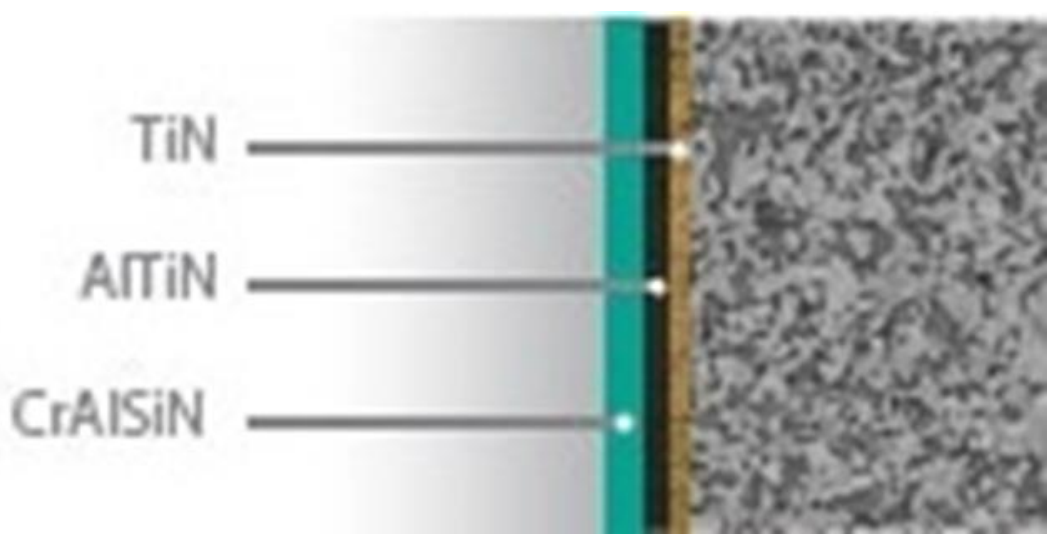

Fig. 6. Layers of Triple-Coating [6]. 


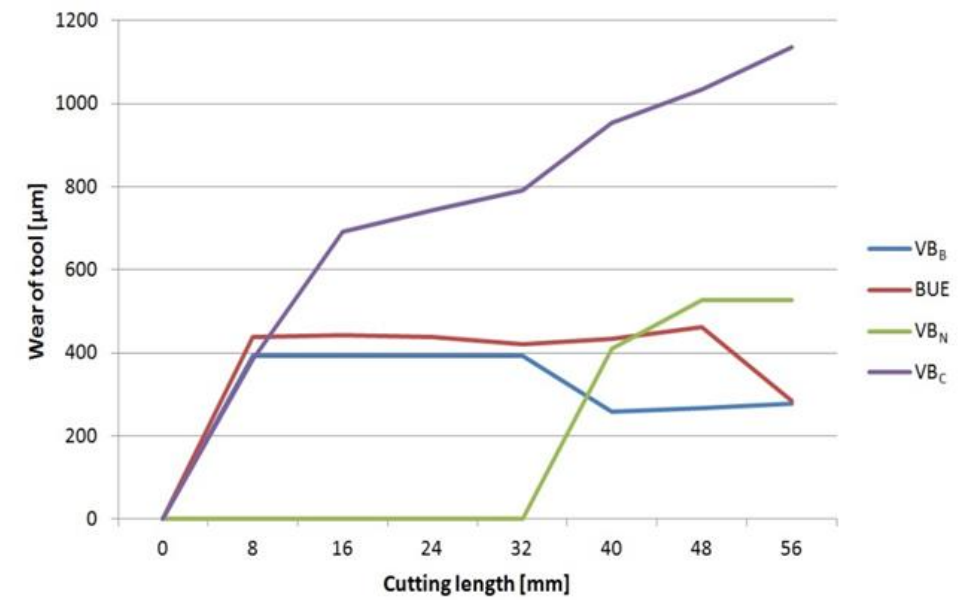

Fig. 7. The wear of cutting tool with Triple-Coating $\left(\mathrm{K} \mathrm{r}=45^{\circ}\right)$.

It is apparent from these results that wear VB has been reduced by almost one half. Lower durability of the nose tool could mean a reduction in material hardness, which could be caused by applying coating to an already hardened material by heat treatment. The temperature of the coating process could have caused structural changes with lowering hardness properties.

\section{Evaluation of the tool wear}

Surface of the cutting tool is scanned with 3D measuring system IFM G4. Output data are evaluated for changes in dimensions and material loss. The results are summed up in Fig. 8, which is showing the distribution of these changes. Images also show enormous nose wear. The wear is attributed to a deficient resistance to abrasion and to insufficient hardness of material treated for hardness.

Minimal improvement in efficiency of cutting property occurs as opposed to a cutting tool made without the thin layer. There is a noticeable increase in the wear of the main cutting edge made out of Ni-Mo steel as opposed to the tool made out of the high speed cutting steel.

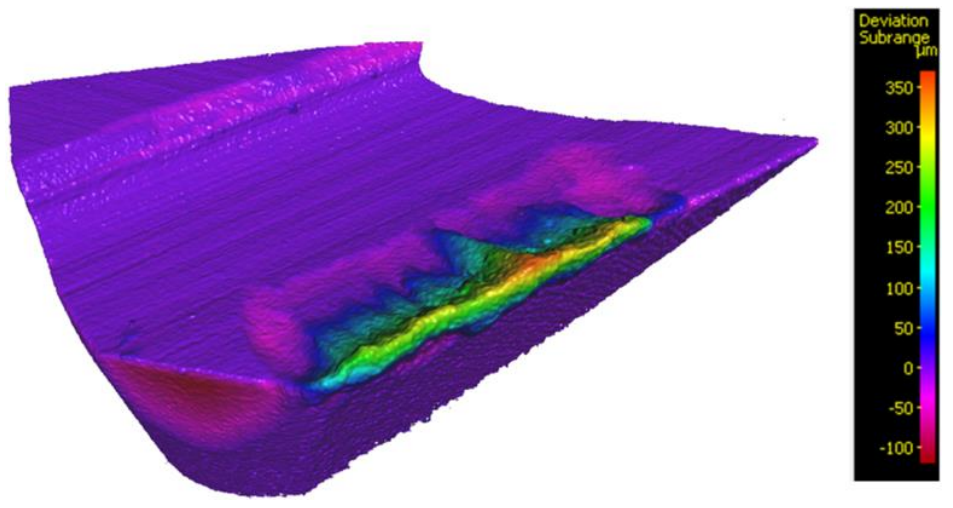

Fig. 8. Dimensional change of the coated cutting tool

\section{Conclusion}

A thin layer of Triple-Coating technology improved the tool's cutting properties and reduced the formation of BUE on the edge of the cutting tool. Nevertheless this is true only until the discovery of the base material of the cutting tool. After of few millimeters of the edge's engagement, the Triple-Coating layers started to peel off. This was because the Ni-Mo hardened steel was not hard enough to support the coating layer.

The increased nose wear on the coated edge indicated reduction of hardness of the coated tool. Coating was applied to a tool previously hardened by heat treatment. Therefore the repeated exposure to heat during the coating process could have played a role in the structural change, which influenced the material's hardness. This could not be confirmed due to a lack of additional information at this time.

The coating process of the tested sample not treated by heat confirmed that the process itself could be utilized for the very heat treatment of steel. This fact could be utilized to further reduce the cost of tools made out of the special Ni-Mo steel. Evaluation of the Ni-Mo steel proved that Ni-Mo steel does not attain the same cutting properties as the high speed cutting steel. Nevertheless this steel is still under development and the optimal cutting-parameters will be searched. [9] 


\section{Acknowledgements}

This paper is based upon work sponsored by project "Regionální technologický institut" reg. no. CZ.1.05/2.1.00/03.0093 and project SGS-2013-031

\section{References}

[1] T. Votáp, J. Peterka, V. Šimna, M. Kuruc, The Influence of Different Types of Copy Milling on the Surface Roughness and Tool Life of End Mills, In Procedia Engineering. Vienna: Elsevier, 2015. s. 868-876, ISSN: $1877-7058$

[2] V. Schorník, M. Daňa, I. Zetková, The Influence of the Machined Surface Quality When the CFRP is Machined, In Procedia Engineering. Vienna: Elsevier, 2015. s. 1270-1276. ISBN: 978-3-901509-99-5 , ISSN: 1877-7058

[3] Modern Metal Cutting. A Practical Handbook, Sandvik Coromant Publ. Fair Lawn, 1996

[4] Thermal Cycle Diagram, online [date 2015-09-15], Available from: http://www.doerrenberg.de/uploads/tx_c1x1downloads/1.3343_en.pdf

[5] B. Li, A review of tool wear estimation using theoretical analysis and numerical simulation technologies. Int. Journal of Refractory Metals and Hard Materials 35 (2012) 143-151

[6] SHm, online [date 2015-08-20], Available: http://www.shm-cz.cz/pvd-povlaky-a-sluzby/pvdpovlaky/triplecoatings-cr/

[7] High-speed Steel W. NR. 1.3343, online [date 2015-08-13], Available from: http://www.jkz.cz/en/node/441

[8] B. Y. Lee, Y. S. Tarng, Cutting-parameter selection for maximizing production rate or minimizing production cost in multistage turning operations, Journal of Materials Processing Technology 105 (2000) 61-66

[9] H. Juan, S. F. Yu, B. Y. Lee, The optimal cutting-parameter selection of production cost in HSM for SKD61 tool steels, International Journal of Machine Tools \& Manufacture 43 (2003) 679-686

A.1. The geometry of the Turning Tool

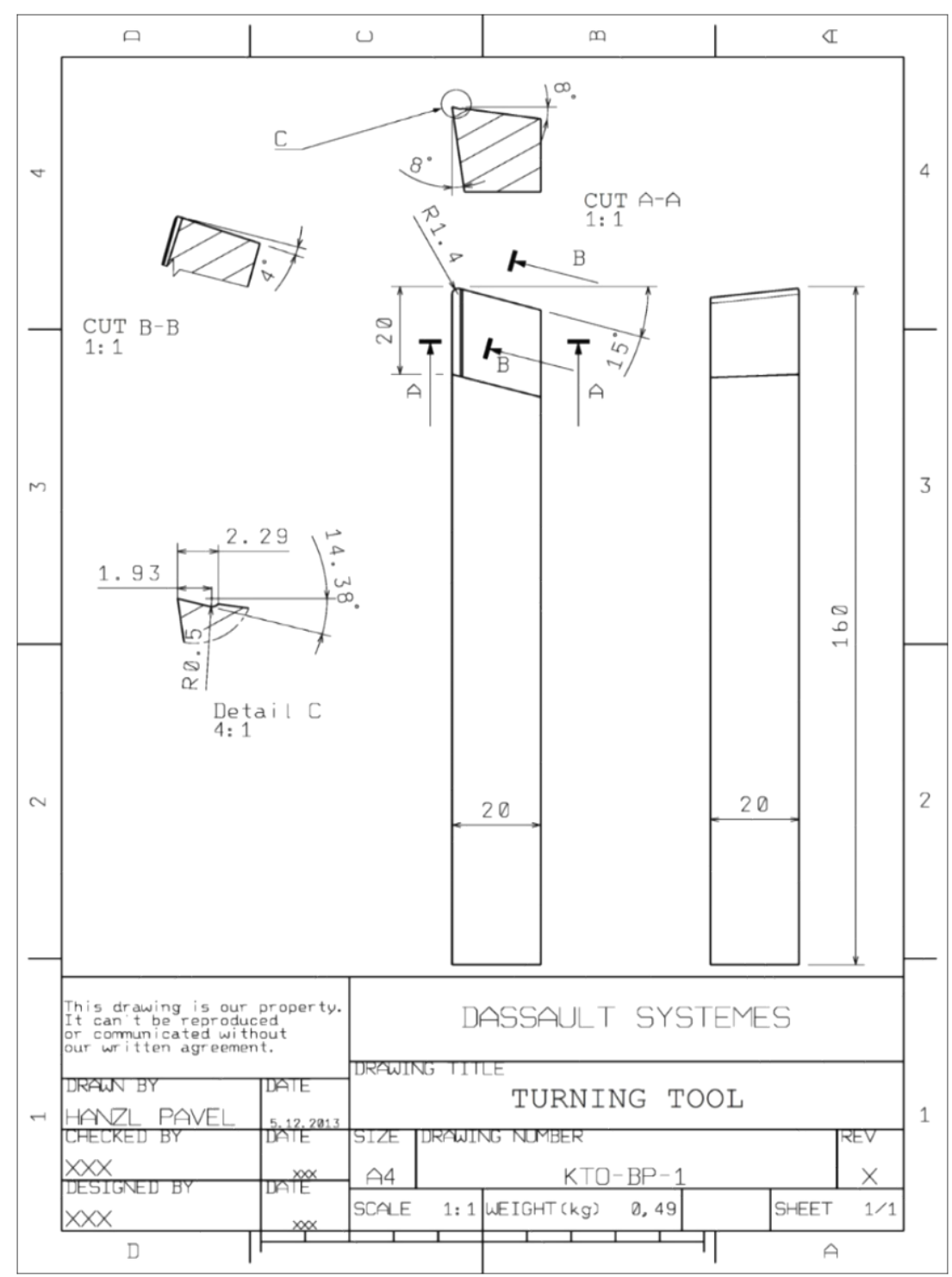

